\title{
CHRONIC MYELOID LEUKAEMIA IN A CHILD PRESENTING AS ACUTE POLYARTHRITIS
}

\author{
BY \\ G. A. BEDWELL and A. M. DAWSON \\ From Charing Cross Hospital, London
}

(RECEIVED FOR PUBLICATION AUGUST 26, 1953)

It is well known that recurrent polyarthritis may occur in leukaemia of childhood, either as a presenting feature or during the course of the disease. The clinical picture, which often suggests rheumatic fever, has frequently been reported (Aisner and Hoxie, 1948; Baldridge and Awe, 1930; Poynton and Lightwood, 1932) and well reviewed by Dresner (1950). Many of these cases were of acute or subacute lymphatic leukaemia with an aleukaemic blood picture and only a few were of the myeloid type. It is rare in adults and little has been written about the pathological changes in the joints involved.

The following case is therefore thought worthy of record in that recurrent polyarthritis was the presenting feature in a child with chronic myeloid leukaemia which subsequently entered the terminal acute phase of the disease. Necropsy revealed leukaemic infiltration of the synovia of the two joints examined histologically.

\section{Case History}

In June, 1952, an 8-year-old schoolgirl developed joint pains and pyrexia and was admitted to another hospital two days after the symptoms started. Her mother stated that the abdomen had been swollen for one year but otherwise the child had been in good health.

Clinical examination showed a thin, pale child with a temperature of $103^{\circ} \mathrm{F}$. and a pulse rate of 132 per minute. There was one enlarged lymph node in the left axilla. The spleen was grossly enlarged and extended into the pelvis. The liver was palpable two fingerbreadths below the costal margin. The skin over both knee joints and the right ankle joint was hot, while the left ankle joint was hot, red and swollen; movements of these joints were limited by pain. There were no other abnormal clinical findings. The blood picture was that of chronic myeloid leukaemia. A clinical diagnosis of chronic myeloid leukaemia and acute rheumatic fever was made. She was treated with aspirin, 15 grains four-hourly, and within 24 hours the temperature had settled and the joint condition subsided. Two days after admission she developed signs of splenic infarction with abdominal pain, tenderness over the spleen and a splenic friction rub. Some days later she developed a transient pericardial friction rub.
On July 1, 1952, she was admitted to Charing Cross Hospital. Clinical examination and laboratory findings confirmed the diagnosis of chronic myeloid leukaemia but there were no overt joint changes.

Special investigations showed; haemoglobin $57 \%$ $(8.4$ g. $\%$ ), leucocytes, 133,200 per c.mm. (myeloblasts $0.5 \%$, premyelocytes $7 \cdot 5 \%$, myelocytes $16.0 \%$, metamyelocytes $15.0 \%$, polymorphs $50.0 \%$, eosinophils $3 \cdot 0 \%$, basophils $3 \cdot 5 \%$, lymphocytes $4 \cdot 5 \%$ ). The antistreptolysin titre was normal. No $\beta$-haemolytic streptococci were grown on a throat swab. The serum uric acid was $2.4 \mathrm{mg}$. \%. A radiograph of the long bones and pelvis revealed no evidence of leukaemic changes on two occasions.

Five doses of deep $x$ rays to the splenic region were given and resulted in a slight diminution in the size of the spleen and a reduction in the total white cell count. This showed on July 31 , haemoglobin $42 \%(6 \cdot 2$ g. \%), white cells 33,900 (premyelocytes $2 \cdot 0 \%$, myelocytes $23 \cdot 5 \%$, metamyelocytes $6.0 \%$, polymorphs $63.0 \%$, eosinophils $1.5 \%$, basophils $1.0 \%$, lymphocytes $3.0 \%$ ), and platelets 188,800 . She was transfused with five pints of blood after which the haemoglobin rose to $109 \%(16 \cdot 2 \mathrm{~g}$. \%).

During the four months following admission she developed repeated attacks of pyrexia and joint pain affecting the fingers, wrists, elbows, shoulders, knees and ankles, at times accompanied by redness and warmth of the overlying skin with visible swelling of the joints. These attacks were sometimes accompanied by effusion into the joints with temporary periarticular thickening lasting 24 hours to 10 days. Finally the small joints of the left hand and both knees showed permanent periarticular thickening. Movements were always painful and much restricted during the acute phases. The attacks of febrile arthritis were not influenced by continual salicylate therapy of 90 grains daily (body weight, $52 \mathrm{lb}$.) while in Charing Cross Hospital. During the last six weeks of the illness her condition progressively worsened with irregular fever, emaciation, increasing anaemia and purpura; the superficial lymph nodes became enlarged and there was persistent localized pain and tenderness over the lower end of the left femur. The terminal white cell count showed 154,000 leucocytes per c.mm. of which $54 \%$ were myeloblasts. She died on November 2, 1952.

Necropsy.-The essential features were anaemia of all organs with widespread petechial haemorrhages into the 
skin, pleura, pericardium and urinary bladder. All lymph nodes, both superficial and in the thorax and abdomen, were obviously enlarged. The spleen was grossly enlarged and weighed 1,090 g. and the liver was

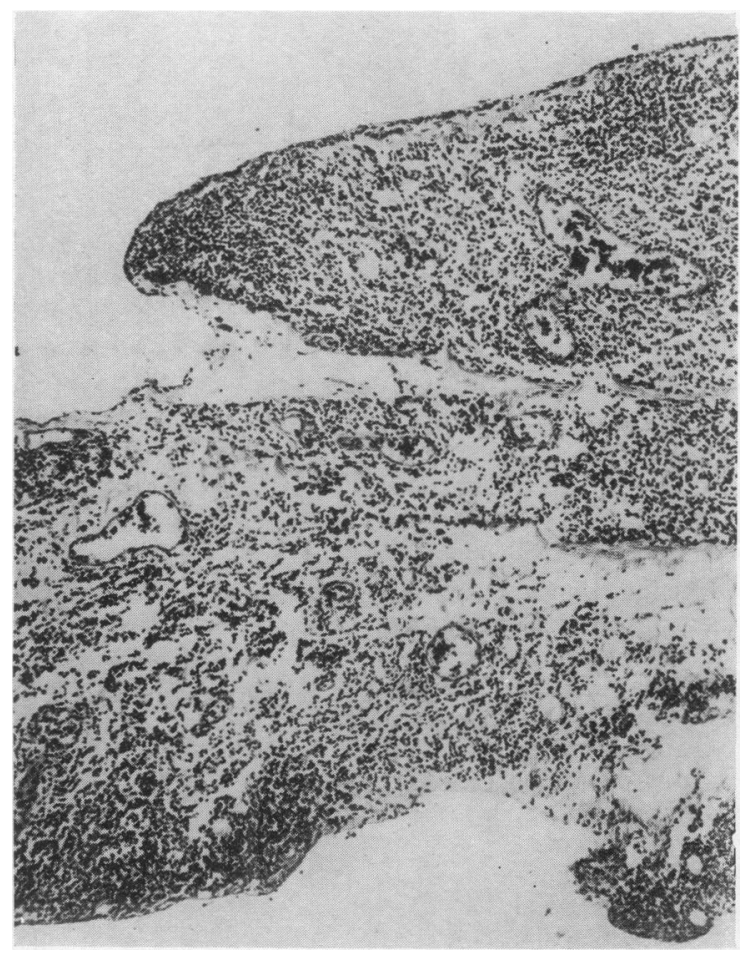

FIG. 1.-Synovial membrane infiltrated with immature white cells Haematoxylin and eosin $\times 70$.

also enlarged but there was no macroscopical evidence of leukaemic infiltration. There were scattered leukaemic deposits in the vertebral, sternal and femoral bone marrow; the periosteum of the left femur was thickened due to leukaemic infiltration. The synovial membranes of the left knee and right elbow joints were oedematous and covered with scattered petechial haemorrhages, and histology showed extensive infiltration with leukaemic cells (Figs. 1 and 2). There was no microscopic evidence of rheumatic heart disease.

\section{Discussion}

The history of apparent good health with swelling of the abdomen for one year, the gross enlargement of the spleen and the original blood films all supported the diagnosis of chronic myeloid leukaemia. These findings were so typical that marrow examination was considered unjustified. The associated clinical diagnosis of acute rheumatism as suggested by flitting polyarthritis and pericarditis was not substantiated by the subsequent progress of the disease, the response to salicylates, the laboratory findings and finally by the necropsy.

Histological reports of the joints involved in leukaemia are, as stressed by Dresner (1950), remarkably scarce. He reported one case of leukaemic infiltration of the synovium and suggested that this was responsible for the joint manifestations in this disease. However, others have found no evidence of pathology in the affected joints and have attributed symptoms to nearby bony changes (Poynton and Lightwood, 1942; Bichel, 1948). Our case supports the view that leukaemic infiltration of the synovium of the joint can be responsible for the manifestations that occur in leukaemia, as both joints examined histologically showed this change. The persistent pain over the lower end of the femur apparently resulted from leukaemic infiltration of the periosteum.

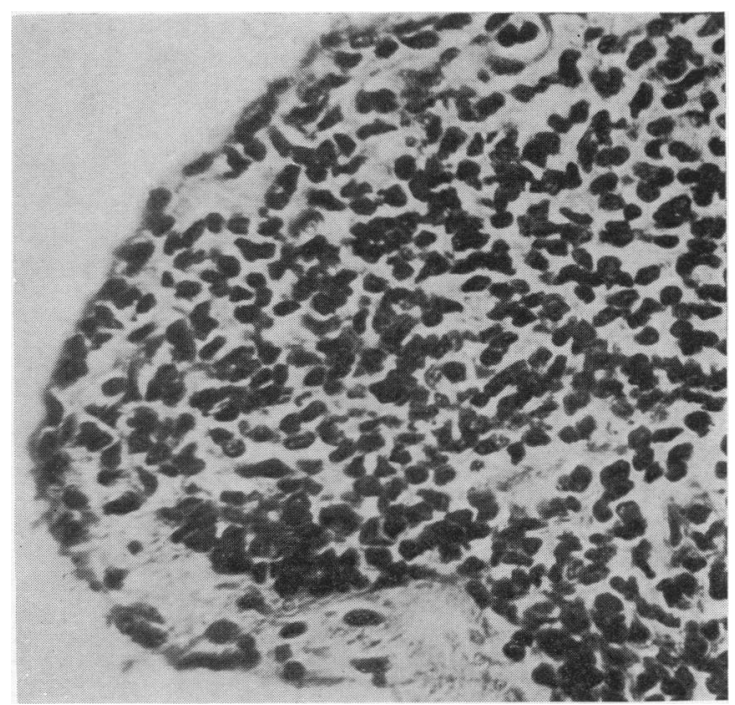

Fig. 2.-Inset of Fig. $1 \times 500$.

\section{Summary}

A case of chronic myeloid leukaemia in a child, which presented as acute polyarthritis is described. Histology showed leukaemic infiltration of the synovia of the two joints examined.

We would like to thank Dr. E. C. Warner for his permission to report this case and Dr. J. H. Shore for the post-mortem findings.

\section{REFERENCES}

Aisner, M. and Hoxie, T. B. (1948). New Engl. J. Med., 238, 733 Baldridge, C. W. and Awe, C. D. (1930). Arch. intern. Med., 45, 161 Bichel, J. (1948). Acta haemat. Basel, 1, 153 .

Dresner, E. (1950). Quart. J. Med., 19, 339.

Poynton, F. J. and Lightwood, R. (1932). Lancet, 1, 1192. 